\section{The Use of a Low-Dose Ketamine Infusion in the Management of an Acute Pain Crisis in a Patient with Sickle Cell Disease}

\section{Bryan Simmons, Mark Hoeft and Jingping Wang*}

Department of Anesthesia, Critical Care and Pain Medicine, Massachusetts General Hospital, Harvard Medical School, Boston, USA

\begin{abstract}
Sickle Cell Disease (SCD) affects over 90,000 Americans. Pain management of vaso-occlusive pain crises in SCD is a difficult task. Many of the patients suffer from chronic pain and require chronic opioid use, leading to a high incidence of opioid tolerance. In addition, patients may exhibit Opioid-Induced Hyperalgesia $(\mathrm{OIH})$, a phenomenon in which opioid use leads to increased sensitivity to noxious stimuli. Both factors contribute to difficulty in managing acute pain exacerbations. Here, we present a patient with SCD who was admitted for an acute pain crisis and the use of ketamine as an adjunct in the pain management of that vaso-occlusive pain crisis. A review of the literature regarding the use of low-dose ketamine in the management of vaso-occlusive pain crises is presented.

Keywords: Acute vaso-occlusive pain crisis; Ketamine infusion; Opioid-induced hyperalgesia; Sickle cell disease
\end{abstract}

\section{Introduction}

Sickle Cell Disease (SCD) [1] is a major public health concern, accounting for roughly 75,000 hospital admission per year in the United States with a cost of roughly $\$ 475$ million dollars annually [2]. Acute vaso-occlusive pain crises are relatively common reasons for hospital admission of sickle cell patients. Many of these patients struggle with chronic pain requiring chronic opioid therapy, which makes treating these painful episodes even more challenging. There is no evidence-base treatment strategy that has proven effective in treating acute pain crises in SCD. Traditional approaches to pain management in SCD have relied heavily upon opioids and non-opioids, such as Non-Steroidal Anti-Inflammatory Drugs

*Corresponding author: Jingping Wang, Department of Anesthesia, Critical Care and Pain Medicine, Massachusetts General Hospital, Harvard Medical School, Boston, USA, Tel: +1 6176432729; Fax: +1 6177267536; E-mail: jwang23@partners.org

Citation: Simmons B, Hoeft M, Wang J (2015) The Use of a Low-Dose Ketamine Infusion in the Management of an Acute Pain Crisis in a Patient with Sickle Cell Disease. J Anesth Clin Care 2: 008.

Received: March 14, 2015; Accepted: July 13, 2015; Published: July 27, 2015
(NSAIDs) and acetaminophen [3]. Despite these approaches, many sickle cell patients report inadequate pain control with high re-admission rates. Here, we describe the use of a low-dose ketamine infusion as an adjunct for managing acute vaso-occlusive pain in a 24-year old woman with SCD. Ketamine was effective in decreasing Numeric Rating Scale (NRS) pain scores and opioid consumption prior to its discontinuation. A handful of other cases reports show similar promise with the use of ketamine in the treatment of vaso-occlusive crises. The ability of ketamine to limit opioid tolerance, $\mathrm{OIH}$, and central sensitization make it a suitable analgesic adjunct in this patient population. Nonetheless, the side effect profile of ketamine may limit its usefulness.

\section{Case Report}

A 24-year-old African-American woman with a history of SCD (HbS/beta ${ }^{0}$ thalassemia) complicated by bilateral a vascular necrosis of her humeral heads and multiple admissions for pain crises presented with severe chest pain. She described this pain as constant, substernal, and pleuritic with radiation to the middle of her back. In addition to her chest and back pain, she reported baseline bilateral hip pain. The pain did not respond to her home regimen of MS Contin $60 \mathrm{mg}$ twice daily and oxycodone $30 \mathrm{mg}$ every 3 hours as needed for pain. Until a few days prior to admission, her pain was stable on this regimen for the previous two months. Her past medical history was notable for multiple prior admissions for vaso-occlusive crises over the previous twelve months. Review of systems was otherwise notable for nausea. Her examination was notable for tenderness along her anterior chest wall as well as her thoracic spine. She was a febrile with satisfactory vital signs. Electrocardiogram and chest $\mathrm{x}$-ray were unremarkable, while chest CT revealed small nodular opacities of the lingula. Complete blood count, reticulocyte count, and urinalysis were unremarkable. Blood and urine cultures were obtained. She was diagnosed with a sickle cell pain crisis with possible pneumonia and admitted for intravenous antibiotics and pain management. She received $6 \mathrm{mg}$ IV morphine in the Emergency Room prior to admission.

Initially, she was placed on her home MS Contin (60mg PO BID) and morphine PCA in addition to acetaminophen and ibuprofen. Over the subsequent seven days, the patient continued to have poor pain control despite escalating doses of opioids. Given the poor response to opioids, a low-dose ketamine infusion (3-6 mcg/ $/ \mathrm{kg} / \mathrm{min}$ ) was started. Prior to initiation of the ketamine infusion, the daily opioid consumption was $204 \mathrm{mg}$ in IV Morphine equivalents and NRS pain scores were 9-10 out of 10 . On the first, second, and third day of the ketamine infusion, the patient's daily opioid requirement was 190,120 , and $132 \mathrm{mg}$ IV morphine equivalents, while her NRS pain scores were 10, 8, and 7 out of 10, respectively (Figure 1). The first evening of the ketamine infusion, the patient reported five hours of uninterrupted sleep for the first time during her hospitalization. The ketamine infusion was discontinued after three days due to tinnitus and a subjective heaviness of her lower extremities, which was attributed to the ketamine. Following discontinuation of the ketamine infusion, the pain scores increased slightly, and she was transitioned to a fentanyl PCA. Over the subsequent two days, her opioid 
requirement continued to decline even though her pain scores remained unchanged. Four days following discontinuation of the ketamine infusion, opioid requirements rebounded to a peak of $250 \mathrm{mg}$ of IV morphine equivalents per day. From there, her opioid requirements gradually declined and she was transitioned to an oral regimen on hospital day 17 . She was ultimately discharged home on MS Contin 60mg PO twice daily and oxycodone 45mg PO every 6 hours as needed for pain on hospital day 30 .

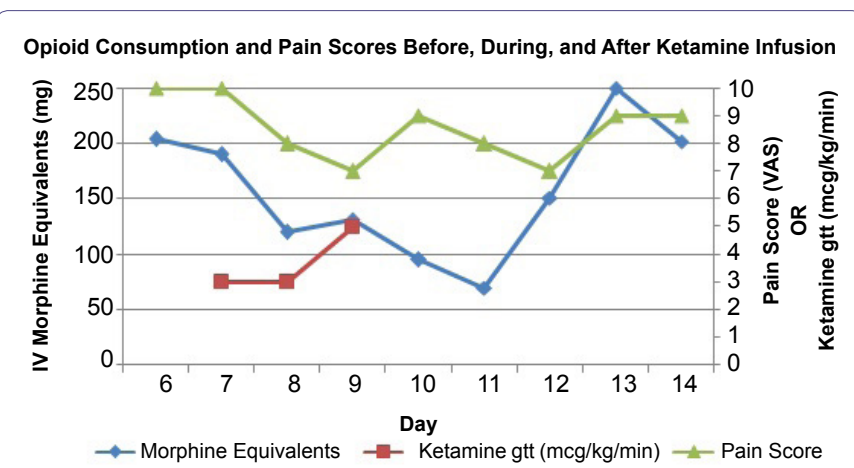

Figure 1: Opioid consumption and pain scores before, during, and after ketamine infusion.

\section{Discussion}

Currently, there is no treatment strategy or algorithm that has proven effective in treating acute pain crises in SCD. Current recommendations for treating acute vaso-occlusive pain crises include rapid initiation of parenteral opioids for severe pain and the use of Non-Steroidal Anti-Inflammatory Drugs (NSAIDs) for mild-to-moderate pain in the absence of contraindications [4]. Outpatient management of chronic pain associated with sickle cell disease follows the three-step ladder set forth by the World Health Organization for chronic cancer-related pain [5]. Mild pain is treated with non-opioid medication and adjuncts while more severe pain necessitates the addition of opioids. Unfortunately, these approaches often leave sickle cell patients with inadequate pain control. A prospective study revealed adults with SCD continue to have pain on greater than $50 \%$ of days over a 6 -month period, while $30 \%$ of patients have pain on more than $95 \%$ of the days [6]. When adult SCD patients are admitted to the hospital for pain crises, the average length of stay is 7.5 days with a $50 \%$ re-admission rate within one month following discharge [7]. Clearly, poorly-controlled pain accounts for a large portion of the morbidity associated with SCD, necessitating better pain regimens.

Many patients with SCD require chronic opioid medication for pain control putting them at risk of opioid-induced hyperalgesia and opioid tolerance. Although these are two distinct phenomena, they both contribute to the decreased analgesic effect of opioid medication [8]. Whereas tolerance is associated with a loss of drug potency and a rightward shift in the dose-response curve, $\mathrm{OIH}$ is characterized by increased pain with opioid exposure and a downward shift in the dose-response curve [9]. Animal studies have demonstrated the development of both $\mathrm{OIH}$ and opioid tolerance have a common mechanistic pathway involving activation of Excitatory Amino Acid (EAA) receptors, including the NMDA and non-NMDA (AMPA/kainite) receptors [10]. Thus, blocking one of these receptors may decrease opioid tolerance and $\mathrm{OIH}$ rendering opioids more effective in patients requiring chronic opioid therapy. This offers one mechanism by which ketamine, a NMDA receptor antagonist, may function to provide analgesia in patients with sickle cell disease. In fact, ketamine has been implicated in the reduction of opioid tolerance and $\mathrm{OIH}[11]$.

There may also be an analgesic effect of ketamine that is independent of exogenous opioids. Upon noxious stimulation, first-order neurons release the excitatory amino acid glutamate, which activates ascending second-order neurons via AMPA and NMDA receptors [12]. In acute nociceptive stimulation, AMPA serves as the predominate receptor through which this signaling pathway proceeds; however, with continued stimulation, the NMDA receptor becomes more involved. Antagonizing the NMDA receptor with ketamine could potentially block some of the noxious stimuli. In addition, the NMDA receptor has been implicated in changes that occur in the spinal cord during repetitive noxious stimuli leading to central sensitization [12]. Wind-up, a phenomenon by which repetitive noxious stimulation over a period of seconds leads to a progressive increase in nociceptive response, is inhibited by NMDA receptor antagonism [13]. Similarly, NMDA receptor antagonism has been shown to prevent long-term potentiation, another phenomenon that occurs with repetitive stimulation and leads to potentiation of noxious stimuli [14]. Unlike wind-up; however, the effects of long-term potentiation are much longer lasting. These mechanisms may help to explain the efficacy of using ketamine in sickle cell disease pain management.

Low-dose ketamine infusions have proven effective in treating pain in other patient populations that are opioid tolerant such as patients with chronic cancer pain $[15,16]$. In addition, low-dose ketamine infusions have shown efficacy in acute post-operative pain $[17,18]$. However, data on the use of low-dose ketamine infusions for treatment of SCD pain crises is limited. Review of the literature reveals three case reports and two case series on the use of low-dose ketamine infusions in the management of acute pain crises in SCD (Table 1) [19-23]. The largest case report was done by Tawfic et al., [20] which was a retrospective review of nine adult patients with vaso-occlusive crises admitted to the ICU for inadequate pain control [19]. In addition to their existing analgesic regimen, a ketamine $(0.2-0.25 \mathrm{mg} / \mathrm{kg} / \mathrm{hr})-$ midazolam $(0.5-1.0 \mathrm{mg} / \mathrm{hr})$ infusion was initiated. The authors found a statistically significant reduction in IV opioid requirements (145.6 \pm 16.5 to $112 \pm 12.2 \mathrm{IV}$ morphine equivalents) and pain scores $(8-9 / 10$ to $5-7 / 10)$. Furthermore, eight out of nine of the patients reported improved sleep following the start of the infusion. Side effects included nausea in five patients and psychomimetic effects in one patient. From a retrospective chart review at a single medical center, Zempsky et al., [22] reported five pediatric patients, ages 10-18, who were admitted with vaso-occlusive crises and received an IV ketamine infusion $(0.06$ to $0.1 \mathrm{mg} / \mathrm{kg} / \mathrm{hr})$ to supplement their analgesic regimen [22]. Of these five patients, two achieved adequate pain control, while the ketamine was discontinued in the others due to a side effects or lack of efficacy. Of the 17 reported cases in the literature, the use of ketamine in the management of acute pain crises of SCD has shown to improve pain scores in all but three cases. Similarly, only three of the cases in the literature failed to show an improvement in opioid consumption. Interestingly, improvement in sleep was commonly noted in patients receiving benefit from ketamine. Side effects were usually mild but included nausea and nystagmus; however, there was one case of psychomimetic effects, while one case reported dysphoria leading to discontinuation. There was one case of hypertension and unresponsiveness, which was attributed to an inadvertent ketamine bolus. 
Citation: Simmons B, Hoeft M, Wang J (2015) The Use of a Low-Dose Ketamine Infusion in the Management of an Acute Pain Crisis in a Patient with Sickle Cell Disease. J Anesth Clin Care 2: 008.

- Page 3 of 4 •

\begin{tabular}{|c|c|c|c|c|c|c|}
\hline References & No. of Patients & Ketamine Dose & $\begin{array}{l}\text { Opioid Use (Morphine } \\
\text { Equivalents) }\end{array}$ & Pain Scores & Hospital Length of Stay & Side Effects \\
\hline Uprety et al. [19] & 1 & Not specified & Not specified & $\begin{array}{c}\text { Reduced } \\
7-10 / 10 \text { to } 4-6 / 10\end{array}$ & $\begin{array}{c}37 \text { days total; } \\
7 \text { days after start of } \\
\text { ketamine }\end{array}$ & None \\
\hline Tawfic et al. [20] & 9 & $\begin{array}{l}0.25 \mathrm{mg} / \mathrm{kg} \text { bolus }+0.2-0.25 \mathrm{mg} / \mathrm{kg} / \mathrm{h} \\
(+ \text { midazolam })\end{array}$ & $\begin{array}{l}\text { Decreased (Avg: } \\
145 \mathrm{mg} / 24 \mathrm{~h} \text { to } \\
112 \mathrm{mg} / 24 \mathrm{~h})\end{array}$ & $\begin{array}{c}\text { Reduced } \\
8-10 / 10 \text { to } 5-7 / 10\end{array}$ & Average not reported & $\begin{array}{c}\text { Psychotomimetic } \\
\text { manifestations } \\
(1 / 9) \\
\text { Nausea }(5 / 10)\end{array}$ \\
\hline Meals et al. [21] & 1 & Bolus +infusion $(9-24 \mathrm{mg} / \mathrm{hr})$ & $\begin{array}{l}\text { Decreased }(172 \mathrm{mg} / 24 \mathrm{~h} \\
\text { to } 88 \mathrm{mg} / 24 \mathrm{~h})\end{array}$ & Reduced & $\begin{array}{l}14 \text { days total; } \\
3 \text { days after start of } \\
\text { ketamine }\end{array}$ & Nystagmus \\
\hline $\begin{array}{l}\text { Zempsky et al. [22] } \\
\text { (pediatric) }\end{array}$ & 5 & $0.06-0.2 \mathrm{mg} / \mathrm{kg} / \mathrm{hr}+/-$ initial bolus & $\begin{array}{l}\text { No change }(3 / 4) \\
\text { Reduced }(1 / 4)\end{array}$ & $\begin{array}{l}\text { No change }(3 / 5) \\
\text { Reduced }(2 / 5)\end{array}$ & $6-11$ days total & $\begin{array}{c}\text { Dysphoria (1/5), } \\
\text { Nystagmus, (1/5), } \\
\text { HTN }(1 / 5)\end{array}$ \\
\hline Jennings et al. [23] & 1 & $15-50 \mathrm{mg} \mathrm{PO}$ every 6 hours & $\begin{array}{c}\text { Decreased } \\
3260 \mathrm{mg} / 24 \text { hours to } \\
650 \mathrm{mg} / 24 \text { hours over } \\
5 \text { days }\end{array}$ & Reduced & $\begin{array}{l}12 \text { days total; } 5 \text { days } \\
\text { after start of PO ketamine }\end{array}$ & None \\
\hline
\end{tabular}

Table 1: Ketamine infusions in the management of acute SCD crises literature: Summary of reports and treatment approaches.

In the present case, the patient continued to have poor pain control in the face of increasing doses of IV opioids as well as NSAIDs and acetaminophen. Similar to many people with SCD, this patient was opioid tolerant and may have suffered from OIH or central sensitization. A low-dose ketamine infusion was started as an adjunct to the pain regimen. Forty-eight hours following initiation of the ketamine infusion, her twenty-four hour opioid requirement decreased by $41 \%$, and her NRS pain score decreased by two. In addition, the patient reported five hours of uninterrupted sleep for the first time during her admission. This reduction in opioid requirement continued while low-dose ketamine was infusing and for two days following termination of the ketamine infusion. The patient's pain score did transiently increase following discontinuation of the ketamine infusion, at which time she was transitioned to a fentanyl PCA. It is uncertain whether this transition had any additional impacted on the patient's pain scores or opioid consumption. Nonetheless, three days following termination of the ketamine infusion, her opioid requirement increased abruptly. It appears as though the effect of ketamine persisted after its discontinuation, an observation consistent with other studies evaluating the use of ketamine for post-operative pain [24]. In addition, the increase in pain scores following discontinuation of the low-dose ketamine infusion supports the notion that the initial reduction in pain scores and opioids are attributable to the ketamine as opposed to natural resolution of her pain crisis.

The ketamine infusion was discontinued after the patient reported a subjective heaviness in her lower extremities in addition to intermittent tinnitus. It is unclear whether these symptoms were due to the ketamine. First, the symptoms the patient reported are not typical side effects of ketamine. Second, the onset of her symptoms started 3 days after the start of the ketamine infusion and persisted despite ketamine discontinuation. Such a temporal relation argues against ketamine as being the cause. Nonetheless, the infusion was discontinued. After peaking at $250 \mathrm{mg}$ IV morphine equivalents on day 13 , her opioid requirements gradually declined, she was transitioned to a PO regimen and later discharged home.

As shown in both this case and the literature review, the side effects of ketamine can limit its usefulness as an analgesic in SCD. While side effects are much less common when used in analgesic doses as opposed to anesthetic doses, they still occur at a reasonable frequency at sub-anesthetic doses. Common side effects include alteration in sensorium including dissociative experiences, vivid dreams, and delirium; sympathomimetic effects including hypertension and tachycardia; nystagmus; nausea and vomiting; increased intracranial pressure; hypersalvation; and increased muscle tone and muscle spasms [25]. In an attempt to attenuate or eliminate these side effects, many pharmacologic agents have been studied [26]. Benzodiazepenes have consistently shown to be effective in attenuating the psychomimetic effects of ketamine [26,27]. Hypersalvation can be obviated with premedication with antisialogogue [25], while the sympathomimetic effects can be partially attenuated with pretreatment of benzodiazepenes or clonidine $[28,29]$. In combination with these medications, the usefulness and side effect profile of ketamine is much improved, making it much more suitable for treatment of vaso-occlusive pain crises.

\section{Conclusion}

Managing vaso-occlusive pain crises in SCD is a challenging task. There is a lack of evidence-based approaches to pain management in SCD; however, traditional methods rely heavily upon opioids, leading to opioid tolerance and OIH. The traditional approaches to pain control frequently prove to be inadequate, contributing to the morbidity of SCD. Based upon a limited number of case reports, ketamine may be a useful adjunct in the management of SCD pain crises; however, side effects may limit its usefulness. Further investigation is needed in both the adult and pediatric population to evaluate the role of ketamine in the treatment of pain crises in SCD.

\section{References}

1. Sickle Cell Disease (SCD) (2013) Center for Disease Control and Prevention.

2. Davis H, Moore RM Jr, Gergen PJ (1997) Cost of hospitalizations associated with sickle cell disease in the United States. Public Health Rep 112: 40-43.

3. Field JJ, Knight-Perry JE, Debaun MR (2009) Acute pain in children and adults with sickle cell disease: management in the absence of evidence-based guidelines. Curr Opin Hematol 16: 173-178

4. Yawn BP, Buchanan GR, Afenyi-Annan AN, Ballas SK, Hassell KL, et al (2014) Management of sickle cell disease: summary of the 2014 evidence-based report by expert panel members. JAMA 312: 1033-1048.

5. Ballas SK (2005) Pain management of sickle cell disease. Hematol Oncol Clin North Am 19: 785-802. 
6. Smith WR, Penberthy LT, Bovbjerg VE, McClish DK, Roberts JD, et al. (2008) Daily assessment of pain in adults with sickle cell disease. Ann Intern Med 148: $94-101$

7. Ballas SK, Lusardi M (2005) Hospital readmission for adult acute sickle cell painful episodes: frequency, etiology, and prognostic significance. Am J Hematol 79: 17-25

8. Chu LF, Angst MS, Clark D (2008) Opioid-induced hyperalgesia in humans: molecular mechanisms and clinical considerations. Clin J Pain 24: 479-496.

9. Angst MS, Clark JD (2006) Opioid-induced hyperalgesia: a qualitative systematic review. Anesthesiology 104: 570-587.

10. Mao J, Price DD, Mayer DJ (1994) Thermal hyperalgesia in association with the development of morphine tolerance in rats: roles of excitatory amino acid receptors and protein kinase C. J Neurosci 14: 2301-2312.

11. De Kock M, Lavand'homme $P$, Waterloos $H$ (2001) 'Balanced analgesia' in the perioperative period: is there a place for ketamine? Pain 92: 373-380.

12. Chizh BA, Headley PM (2005) NMDA antagonists and neuropathic pain--multiple drug targets and multiple uses. Curr Pharm Des 11: 2977-2994.

13. Price DD, Mao J, Frenk H, Mayer DJ (1994) The N-methyl-D-aspartate receptor antagonist dextromethorphan selectively reduces temporal summation of second pain in man. Pain 59: 165-174.

14. Sandkühler J, Benrath J, Brechtel C, Ruscheweyh R, Heinke B (2000) Synaptic mechanisms of hyperalgesia. Prog Brain Res 129: 81-100.

15. Fine PG (1999) Low-dose ketamine in the management of opioid nonresponsive terminal cancer pain. J Pain Symptom Manage 17: 296-300.

16. Finkel JC, Pestieau SR, Quezado ZM (2007) Ketamine as an adjuvant for treatment of cancer pain in children and adolescents. J Pain 8: 515-521.

17. Bell RF, Dahl JB, Moore RA, Kalso E (2006) Perioperative ketamine for acute postoperative pain. Cochrane Database Syst Rev 25: CD004603.

18. Subramaniam K, Subramaniam B, Steinbrook RA (2004) Ketamine as adjuvant analgesic to opioids: a quantitative and qualitative systematic review. Anesth Analg 99: 482-495.
19. Uprety D, Baber A, Foy M (2014) Ketamine infusion for sickle cell pain crisis refractory to opioids: a case report and review of literature. Ann Hematol 93 769-771.

20. Tawfic QA, Faris AS, Kausalya R (2014) The role of a low-dose ketamine-midazolam regimen in the management of severe painful crisis in patients with sickle cell disease. J Pain Symptom Manage 47: 334-340.

21. Meals CG, Mullican BD, Shaffer CM, Dangerfield PF, Ramirez RP (2011) Ketamine infusion for sickle cell crisis pain in an adult. J Pain Symptom Manage 42: 7-9.

22. Zempsky WT, Loiselle KA, Corsi JM, Hagstrom JN (2010) Use of low-dose ketamine infusion for pediatric patients with sickle cell disease-related pain: a case series. Clin J Pain 26: 163-167.

23. Jennings CA, Bobb BT, Noreika DM, Coyne PJ (2013) Oral ketamine for sickle cell crisis pain refractory to opioids. J Pain Palliat Care Pharmacother 27: 150-154.

24. Himmelseher S, Durieux ME (2005) Ketamine for perioperative pain management. Anesthesiology 102: 211-220.

25. White PF, Way WL, Trevor AJ (1982) Ketamine--its pharmacology and therapeutic uses. Anesthesiology 56: 119-136.

26. Lilburn JK, Dundee JW, Nair SG, Fee JP, Johnston HM (1978) Ketamine sequelae. Evaluation of the ability of various premedicants to attenuate its psychic actions. Anaesthesia 33: 307-311.

27. Mattila MA, Larni HM, Nummi SE, Pekkola PO (1979) Effect of diazepam on emergence from ketamine anaesthesia. A double-blind study. Anaesthesist 28: 20-23.

28. Cabbabe EB, Behbahani PM (1985) Cardiovascular reactions associated with the use of ketamine and epinephrine in plastic surgery. Ann Plast Surg 15: 50-56.

29. Tanaka M, Nishikawa T (1994) Oral clonidine premedication attenuates the hypertensive response to ketamine. Br J Anaesth 73: 758-762. 